\title{
Comparative Study between the Use of Regular Folic Acid Supplement versus the Use of L-Methyl Folate in Patients with Methyl Tetrahydrofolate Reductase (MTHFR) Gene Mutation with Recurrent Pregnancy Loss
}

\author{
Ahmed Essmat \\ Department of Obstetrics and Gynecology, Faculty of Medicine, Alexandria University, Alexandria, Egypt \\ Email: princeessmat@gmail.com
}

How to cite this paper: Essmat, A. (2021) Comparative Study between the Use of Regular Folic Acid Supplement versus the Use of L-Methyl Folate in Patients with Methyl Tetrahydrofolate Reductase (MTHFR) Gene Mutation with Recurrent Pregnancy Loss. Open Journal of Obstetrics and $G y$ necology, 11, 1104-1111.

https://doi.org/10.4236/ojog.2021.119103

Received: July 28, 2021

Accepted: August 31, 2021

Published: September 3, 2021

Copyright $\odot 2021$ by author(s) and Scientific Research Publishing Inc. This work is licensed under the Creative Commons Attribution International License (CC BY 4.0).

http://creativecommons.org/licenses/by/4.0/

\begin{abstract}
Background: Methylfolate is the active metabolite of folate that is important for DNA repair, synthetized under the effect of MTHFR (methyl-tetrahydro-folatereductase) enzyme. Patients with MTHFR gene mutation have low levels of biologically active methyfolate. Those patients have high homocysteine levels causing vasculopathy and inadequate feto-maternal circulation. Aim of the Work: To predict the potential benefit of use of methylfolate instead of use of the regular folic acid in patients with MTHFR gene mutation with history of RPL (recurrent pregnancy loss). Subjects and Methods: Study was performed on 100 women. All women had experienced at least two consecutive miscarriages first trimester abortion. All patients were positive of having MTHFR gene mutation. Patients were divided into two groups in terms of 1 st trimester drug intake. The 1st group recieved a regular folic acid supplement in a dose of $5 \mathrm{mg}$ per day starting from the day of positive pregnancy test till the end of the first trimester. The 2nd group recieved L-methylfolate supplement in a dose of $1000 \mathrm{mcg}$ per day starting from the day of positive pregnancy test till the end of the first trimester. Then both groups were compared in terms of abortion rates, pregnancy continuation rates and the development of other major obstetric complications. Results: Patients in 1st group had no associated pregnancy related complications in $56 \%$, PE in $14 \%$, PROM in $18 \%$ and PTL in $12 \%$ of cases. On the other hand, patients in 2nd group had no associated pregnancy related complications in $78 \%, \mathrm{PE}$ in $6 \%$, PROM in $8 \%$ and PTL in $8 \%$ of cases $54 \%$ of patients on folate group ended in abortion, while only $16 \%$ of patients on methylfolate
\end{abstract}


group had abortion. $24 \%$ of patients on folate group had PTL, compared to $8 \%$ of patient who had had PTL in methylfolate group. $22 \%$ of patients in the

1 st group continued pregnancy to full term, while $60 \%$ of 2 nd group continued pregnancy to full term. Conclusion and Recommendations: The use of methyl-folate supplement during the first trimester of in patients with history of RPL and positive MTHFR gene mutation should be a routine practice instead of the regular folate supplement as it improves pregnancy continuation rates and decreases occurrence of associated pregnancy co-morbidities as preterm labor and preeclampsia.

\section{Keywords}

MTHFR, Recurrent Pregnancy Loss, Folic Acid, L-Methylfolate

\section{Introduction}

Taking folic acid before conception and for the first three months of pregnancy reduces the risk occurrence and recurrence of neural tube defects (NTD) [1]. The concentration of homocysteine in plasma is a responsive marker of impaired folate status. Several studies also demonstrated that high homocysteine is a risk factor of placenta-mediated diseases, such as preeclampsia, spontaneous abortion, placental abruption, and recurrent pregnancy loss (RPL). Homocysteine could be directly involved by causing vasculopathy leading to inadequate feto-maternal circulation. This is in accordance with the observed relationship between high homocysteine and defective chorionic villous vascularization in mothers with recurrent early pregnancy loss [2]. Methylenetetrahydrofolatereductase (MTHFR) is an enzyme that is involved in the synthesis of 5-methylene tetrahydrofolate, which is a cofactor in the enzymatic formation of methionine from homocysteine. Mutations in MTHFR gene are associated with hyperhomocysteinemia and increased thrombotic tendency [3] [4]. A polymorphism of MTHFR (C677T) leads to an alanine to valine amino acid substitution within the predicted catalytic domain of MTHFR. A recent meta-analysis suggests that the MTHFR C677T rather than A1298C polymorphism may be associated most of pregnancy related complications mentioned above [5]. Taking folic acid supplementation may not be enough to overcome this problem since it is not being activated in the body, therefore taking an already active folate source (methylfolate) is a more reliable way to overcome this deficiency and prevent blood clots (heart attacks, strokes, even miscarriage can be due to blood clots), and improve detoxification systems in the body and especially ensuring you have activated folate in your body around conception to prevent NTD. So, unlike l-methylfolate, regular folic acid should go through series of enzymatic processes to be converted into its active metabolite (l-methylfolate). This is the biologically active form which is transported across the cell membrane into peripheral tissues [6]. 


\section{Subjects and Methods}

Study was performed on 100 women, median age 30 (range 20 - 40), attending the Recurrent Miscarriage Clinic at El-Shatby Maternity Hospital, Alexandria University Hospital over a 12-month period, starting from January 2019 to December 2019, were enrolled in the study after taking a written concent and approval of ethics committee. All women had experienced at least two consecutive miscarriages first trimester abortion ( $<14$ weeks). These ladies were positive of having MTHFR gene mutation (either homozygous or heterozygous). All other causes of RPL were excluded like uterine anomalies and other thrombophilias.

Patients were divided into two groups in terms of $1^{\text {st }}$ trimester drug intake. The $1^{\text {st }}$ group recieved a regular folic acid supplement in a dose of $5 \mathrm{mg}$ per day starting from the day of positive pregnancy test till the end of the first trimester. The $2^{\text {nd }}$ group recieved L-methylfolate supplement in a dose of $1000 \mathrm{mcg}$ per day starting from the day of positive pregnancy test till the end of the first trimester. Both groups were followed up till the end of pregnancy (by abortion or delivery). Both groups were compared in terms of number and type of previous abortions, type of MTHFR gene mutation (homozygous or heterozygous), rates of pregnancy continuation or pregnancy outcome, co-associated morbidity or pregnancy complication like preterm labor (PTL), preeclampsia (PE), premature rupture of membranes (PROM).

\subsection{Inclusion Criteria}

1) Pregnant patients with recurrent pregnancy loss (RPL) with history of two or more consecutive spontaneous abortions.

2) Pregnant patients with positive MTHFR gene mutation (homozygous or heterozygous).

3) Patients who start antenatal care as early as pregnancy is diagnosed in early $1^{\text {st }}$ trimester as early as 5 weeks of gestation.

\subsection{Exclusion Criteria}

1) Patients with other thrombophilic disorders than MTHFR gene.

2) Patients with no prior history of RPL.

3) Patients who vomit regularly and cannot tolerate oral folate therapy.

\section{Aim of the Work}

The aim of the study is to predict the potential benefit of use of methylfolate instead of use of the regular folic acid in patients with MTHFR gene mutation with history of RPL to prevent abortion and to decrease incidence of associated pregnancy complications such as PE, PTL and PROM.

\section{Results}

\section{Statistical Analysis}

The Data was collected and entered into the personal computer. Statistical anal- 
ysis was done using Statistical Package for Social Sciences (SPSS/version 24) software.

The statistical test used as follow:

Arthematic mean, standard deviation, for normally distributed data, comparison between two independent populations were done using independent $t$-test. Chi square test was used to compare between categorized data. The level of significant was 0.05 .

The mean age of folate group was 29.02 years while it was 27.22 years in methylfolate group. The mean number of previous abortionsin $1^{\text {st }}$ group was 2.54 , while it was 2.44 in the $2^{\text {nd }}$ group. 56\% of patients were in the folate group were heterozygous while $44 \%$ were homozygous for MTHFR gene mutation, $42 \%$ of patients were in the methyfolate group were heterozygous while $58 \%$ were homozygous for MTHFR gene mutation (Table 1). Patients in $1^{\text {st }}$ group had no associated pregnancy related complications in 56\%, PE in 14\%, PROM in $18 \%$ and PTL in $12 \%$ of cases. On the other hand, patients in $2^{\text {nd }}$ group had no associated pregnancy related complications in $78 \%, \mathrm{PE}$ in $6 \%, \mathrm{PROM}$ in $8 \%$ and PTL in $8 \%$ of cases (Table 2). Regarding pregnancy outcome, $54 \%$ of patients on folate group ended in abortion, while only $16 \%$ of patients on methylfolate group had abortion. $24 \%$ of patients on folate group had PTL, compared to $8 \%$ of patient who had had PTL in methylfolate group. $22 \%$ of patients in the $1^{\text {st }}$ group continued pregnancy to full term, while $60 \%$ of $2^{\text {nd }}$ group continued pregnancy to full term (Table 3).

Table 1. Comparison between the two studied groups regarding demographic and MTHFR mutation gene type.

\begin{tabular}{|c|c|c|c|}
\hline & $\begin{array}{l}\text { Folate } \\
\text { Group } \\
\text { "n=50" }\end{array}$ & $\begin{array}{l}\text { Methylfolate } \\
\text { Group } \\
\text { "n=50" }\end{array}$ & $P$-value \\
\hline $\begin{array}{l}\text { Age } \\
\text { Range } \\
\text { Mean } \pm \text { S.D. }\end{array}$ & $\begin{array}{c}21-39 \\
29.02 \pm 6.16\end{array}$ & $\begin{array}{c}20-36 \\
27.22 \pm 5.84\end{array}$ & 0.137 \\
\hline $\begin{array}{l}\text { Gravidity } \\
\text { Range } \\
\text { Mean } \pm \text { S.D. }\end{array}$ & $\begin{array}{c}3-5 \\
3.76 \pm 0.82\end{array}$ & $\begin{array}{c}3-5 \\
3.66 \pm 0.77\end{array}$ & 0.532 \\
\hline $\begin{array}{l}\text { Parity } \\
\text { Range } \\
\text { Mean } \pm \text { S.D. }\end{array}$ & $\begin{array}{c}0-1 \\
0.32 \pm 0.47\end{array}$ & $\begin{array}{c}0-1 \\
0.30 \pm 0.46\end{array}$ & 0.831 \\
\hline $\begin{array}{l}\text { Number of previous abortions } \\
\text { Range } \\
\text { Mean } \pm \text { S.D. }\end{array}$ & $\begin{array}{c}2-4 \\
2.54 \pm 0.86\end{array}$ & $\begin{array}{c}1-4 \\
2.44 \pm 0.97\end{array}$ & 0.588 \\
\hline $\begin{array}{l}\text { MTHFR mutation gene type } \\
\text { Heterozygous } \\
\text { Homozygous }\end{array}$ & $\begin{array}{l}28(56.0 \%) \\
22(44.0 \%)\end{array}$ & $\begin{array}{l}21(42.0 \%) \\
29(58.0 \%)\end{array}$ & 0.115 \\
\hline
\end{tabular}


Table 2. Comparison between the two studied groups regarding pregnancy associated complications. (PE: preeclampsia, PROM: premature rupture of membranes, PTL: pre-term labor).

\begin{tabular}{cccccc}
\hline \multirow{2}{*}{ Associated complication } & \multicolumn{2}{c}{ Folate group } & \multicolumn{2}{c}{ Methylfolate group } & \multirow{2}{*}{ P-value } \\
\cline { 2 - 5 } & No. & $\%$ & No. & $\%$ & \\
\hline Non & 28 & 56.0 & 39 & 78.0 & $0.0193^{*}$ \\
PE & 7 & 14.0 & 3 & 6.0 & $0.047^{\star}$ \\
PROM & 9 & 18.0 & 4 & 8.0 & $0.032^{\star}$ \\
PTL & 6 & 12.0 & 4 & 8.0 & 0.061 \\
\hline
\end{tabular}

${ }^{*}$-value $<0.001$. $p$-value is less than 0.001 statistically significant difference.

Table 3. Comparison between the two studied groups regarding pregnancy outcome.

\begin{tabular}{cccccc}
\hline \multirow{2}{*}{ pregnancy outcome } & \multicolumn{2}{c}{ Folate group } & \multicolumn{2}{c}{ Methylfolate group } & \multirow{2}{*}{ P-value } \\
\cline { 2 - 5 } & No. & $\%$ & No. & $\%$ & \\
\hline Abortion & 27 & 54.0 & 8 & 16.0 & \\
Preterm labor & 12 & 24.0 & 12 & 24.0 & $0.001^{*}$ \\
continued till full term & 11 & 22.0 & 30 & 60.0 & \\
\hline
\end{tabular}

${ }^{*} \mathrm{p}$-value $<0.001 . \mathrm{p}$-value is less than 0.001 statistically significant difference.

\section{Discussion}

Folate requirement increases during pregnancy. It is also required for growth and development of the fetus. Folate deficiency has been associated with abnormalities in both mothers (anemia, peripheral neuropathy) and fetuses (congenital anomalies). Dietary supplementation with folic acid preconceptional and during the first trimester has long been known to reduce the risk of neural tube defects (NTDs) in the offspring [1] [7] [8] [9].

Folic acid cannot be synthetizedde novo in the human body; it should be received from food or supplement. Neither folate nor folic acid is metabolically active. Both must be reduced to participate in cellular metabolism. L-5-Methyl tetrahydrofolate (1-methylfolate) is the active metabolite of folate, under the effect of MTHFR enzyme, that circulates in plasma and that is involved in biologic processes [10]. Patients with MTHFR gene mutation are either heterozygous or homozygous [5]. Based on the high incidence of MTHFR genetic polymorphisms in population and concerns about reduced enzymatic activity and the less biologically active 1-methylfolate, more recent research in this area has focused on supplementation with l-methylfolate rather than folic acid as a means of preventing folate-related pathology [6]. Many mutations within the MTHFR gene have been identified; the two most common and important mutations are C677T and A1298C. The former mutation has been shown to cause early pregnancy loss [11].

In this study, the age of patients ranged from 21 to 39 years in first group who received folte supplement; the mean age was 29.02 years, and ranged from 20 to 36 years in second group who received methyl-folte supplement. The age differ- 
ence was not statistically significant between both groups. In a study performed by Zhu [12]; patients aged between 22 and 44 years, with a mean age of 29.8 years. Their control group consisted of 174 patients aged between 21 and 24 years, with a mean age of 28.5 years. The age difference between the two groups was not statistically significant $(\mathrm{P}>0.05)$.

In our study, patients on folate therapy had $2-4$ previous abortion (mean \pm S.D. $2.54 \pm 0.86$ ), while patients on methylfolate had 1 - 4 previous abortions (mean \pm S.D. $2.44 \pm 0.97$ ), with no statistically significant difference between both groups (Table 1). Nearly the same results were reported by Rady [13], who reported $31 \%$ of patients with MTHFR gene mutation had two abortions, and $23 \%$ of patients had five abortions. He also concluded that mutations in the MTHFR gene are a common cause of recurring or non-recurring missed miscarriages.

Miller [14] found that $60 \%$ of American populations are heterozygous (intermediate metabolizers) for MTHFR gene enzymatic activity, whereas up to 25\% of them are homozygous for these genetic variations. Our results were in agreement with him but in Egyptian population. We found that the percent of heterozygous patients ranged from $42 \%$ to $56 \%$, while patients with homozyogous gene mutation ranged from $44 \%$ to $58 \%$ (Table 1 ).

Several studies show the potential benefits of the early use of folic acid in prevention of occurrence of major obstetric complications such as PE, PTL and PROM. Indirect evidence suggests that folate may indeed be important in the timing of labor. In observational studies, a shorter duration of pregnancy has been associated with low serum folate levels [15]. Initial intervention studies focused on multiple micronutrient supplementations and showed a significant reduction in pregnancy complications with such supplementation, including low birth weight, small for gestational age (SGA), and maternal anemia [16]. In our study, there was a significant reduction of the risk of development of these major complications in both groups and reduction risk was more observed in patient group who consumed methyfolate than those who consumed regular folate supplement (Table 2). Patients who consumed methlfolate developed PE in only $6 \%$, PROM in $8 \%$, and PTL in $8 \%$ of cases compared to $14 \%$ developed PE, $18 \%$ developed PROM and 12\% developed PTL in the other group who consumed regular folate therapy.

Patients with MTHFR gene mutation of both types that had history of RPL had lower abortion ( $1^{\text {st }}$ and $2^{\text {nd }}$ trimester types) rate when used methylfolate supplementation than when used a regular folate supplements during the first trimester of pregnancy. Our study proved that clearly when we gave methylfolate supplement in patient with MTHFR gene mutation, the abortion rate was only $6 \%$, compared to $54 \%$ in such patients who received regular folate supplements (Table 3).

The same was for pregnancy continuation rates in both groups. $60 \%$ of patients who received methylfolate continued to full term, while only $22 \%$ of pa- 
tients continued pregnancy to full term in patients who consumed a regular folate supplement (Table 3 ).

\section{Conclusion and Recommendations}

The use of methyl-folate supplement during the first trimester of in patients with history of RPL and positive MTHFR gene mutation should be recommended as a routine practice instead of the regular folate supplement as it improves pregnancy continuation rates and decreases occurrence of associated pregnancy co-morbidities as PTL, PE and PROM.

\section{Conflicts of Interest}

The author declares no conflicts of interest regarding the publication of this paper.

\section{References}

[1] Prevention of Neural Tube Defects (1991) Prevention of Neural Tube Defects: Results of the Medical Research Council Vitamin Study. MRC Vitamin Study Research Group. The Lancet, 338,131-137. https://doi.org/10.1016/0140-6736(91)90133-A

[2] Nelen, W.L., Bulten, J., Steegers, E.A., Blom, H.J., Hanselaar, A.G. and Eskes, T.K. (2000) Maternal Homocysteine and Chorionic Vascularization in Recurrent Early Pregnancy Loss. Human Reproduction, 15, 954-960. https://doi.org/10.1093/humrep/15.4.954

[3] Arruda, V.R., von Zuben, P.M., Chiaparini, L.C., Annichino-Bizzacchi, J.M. and Costa, F.F. (1997) The Mutation Ala677-->Val in the Methylene Tetrahydrofolate Reductase Gene: A Risk Factor for Arterial Disease and Venous Thrombosis. Thrombosis and Haemostasis, 77, 818-821. https://doi.org/10.1055/s-0038-1656059

[4] Boers, G.H. (1997) Hyperhomocysteinemia as a Risk Factor for Arterial and Venous Disease. A Review of Evidence and Relevance. Thrombosis and Haemostasis, 78, 520-522. https://doi.org/10.1055/s-0038-1657580

[5] Yang, B., Fan, S., Zhi, X., et al. (2014) Associations of MTHFR Gene Polymorphisms with Hypertension and Hypertension in Pregnancy: A Meta-Analysis from 114 Studies with 15411 Cases and 21970 Controls. PLOS ONE, 9, e87497. https://doi.org/10.1371/journal.pone.0087497

[6] Greenberg, J.A., Bell, S.J., Guan, Y. and Yu, Y.H. (2011) Folic Acid Supplementation and Pregnancy: More than Just Neural Tube Defect Prevention. Reviews in Obstetrics and Gynecology, 4, 52-59.

[7] Rieder, M.J. (1994) Prevention of Neural Tube Defects with Periconceptional Folic Acid. Clinics in Perinatology, 21, 483-503. https://doi.org/10.1016/S0095-5108(18)30328-2

[8] Pitkin, R.M. (2007) Folate and Neural tube Defects. The American Journal of Clinical Nutrition, 85, 285s-288s. https://doi.org/10.1093/ajcn/85.1.285S

[9] De Wals, P., Tairou, F., Van Allen, M.I., et al. (2007) Reduction in Neural-Tube Defects after Folic Acid Fortification in Canada. The New England Journal of Medicine, 357, 135-142. https://doi.org/10.1056/NEJMoa067103

[10] Pietrzik, K., Bailey, L. and Shane, B. (2010) Folic acid and L-5-Methyltetrahydrofolate: Comparison of Clinical Pharmacokinetics and Pharmacodynamics. Clinical Phar macokinetics, 49, 535-548. https://doi.org/10.2165/11532990-000000000-00000 
[11] Chaithra, P.T., Malini, S. and Kumar, C. (2011) An Overview of Genetic and Molecular Factors Responsible for Recurrent Pregnancy Loss. International Journal of Human Genetics, 11, 217-225. https://doi.org/10.1080/09723757.2011.11886145

[12] Zhu, L. (2015) Polymorphisms in the Methylene Tetrahydrofolate Reductase and Methionine Synthase Reductase Genes and Their Correlation with Unexplained Recurrent Spontaneous Abortion Susceptibility. Genetics and Molecular Research, 14, 8500-8508. https://doi.org/10.4238/2015.July.28.19

[13] Rady, H.A. (2018) Maternal Methyltetrahydrofolate Reductase Gene Mutation in Patients with Missed Abortions. Journal of Taibah University Medical Sciences, 13, 93-96. https://doi.org/10.1016/j.jtumed.2017.04.004

[14] Miller, A.L. (2008) The Methylation, Neurotransmitter, and Antioxidant Connections between Folate and Depression. Alternative Medicine Review, 13, 216-226.

[15] Malinow, M.R., Rajkovic, A., Duell, P.B., Hess, D.L. and Upson, B.M. (1998) The Relationship between Maternal and Neonatal Umbilical Cord Plasma Homocyst(e)ine Suggests a Potential Role for Maternal Homocyst(e)ine in Fetal Metabolism. American Journal of Obstetrics and Gynecology, 178, 228-233. https://doi.org/10.1016/S0002-9378(98)80005-7

[16] Keen, C.L., Clegg, M.S., Hanna, L.A., et al. (2003) The Plausibility of Micronutrient Deficiencies Being a Significant Contributing Factor to the Occurrence of Pregnancy Complications. Journal of Nutrition, 133, 1597s-1605s. https://doi.org/10.1093/jn/133.5.1597S 